\title{
Modeling of SPERT IV Reactivity Initiated Transient Tests in EUREKA-2/RR Code
}

\author{
N. H. Badrun, M. H. Altaf, M. A. Motalab, M. S. Mahmood, and M. J. H. Khan \\ Institute of Nuclear Science \& Technology (INST), Atomic Energy Research Establishment (AERE), Ganakbari, Savar, \\ P.O. Box 3787, Dhaka 1000, Bangladesh \\ Correspondence should be addressed to N. H. Badrun; nhbadrun@yahoo.com
}

Received 28 August 2014; Revised 18 November 2014; Accepted 18 November 2014; Published 9 December 2014

Academic Editor: Arkady Serikov

Copyright (C) 2014 N. H. Badrun et al. This is an open access article distributed under the Creative Commons Attribution License, which permits unrestricted use, distribution, and reproduction in any medium, provided the original work is properly cited.

\begin{abstract}
EUREKA-2/RR code has been used for SPERT IV reactor benchmark calculations against the experimental results provided by IAEA (International Atomic Energy Agency) obtained for a series of transient tests initiated by step insertion of different magnitudes of positive reactivity with varying degrees of different controlled parameters such as reactor initial power, coolant temperature and coolant flow condition. 20 out of 39 tests that fall under forced convection mode have been considered for the present simulation provided the reactor scram system is disabled. Peak power and peak clad temperature due to transient have been calculated and it was found that although peak clad temperature values agreed, the peak power values seem to underestimate the experimental values. Further study appears to be needed to identify the limitations in modeling or examining the effect of input parameters during modeling to obtain the better simulation results.
\end{abstract}

\section{Introduction}

Since SPERT program initiated in 1954, a variety of configurations under a broad range of conditions have been taken into consideration to study transient behavior of nuclear reactors. With the growing need to validate the experimental results, numerical code has got much attention and PARET is one such computer code originally developed for the analysis of SPERT-III experiments in 1969 [1]. Later, this code has been modified incorporating many issues such as selection of flow instability, departure from nucleate boiling, single- and two-phase heat transfer correlations, and a properties library considered more applicable to the low pressures, temperature, and flow rates that enhances the acceptability of the code for its subsequent use in the analysis of transient behavior of research reactor. However, in modeling the research reactor transient condition, the analyst has to consider some conservative assumptions due to lack of experimental data which may lead to false prediction of the real physical phenomenon that takes place in the reactor. One common point that came out from reactor analysis is the importance of proper selection of input parameters such as DNB correlations to obtain the real characteristic of the transient parameters $[2,3]$. In this context, reactivity initiated transient analysis code EUREKA-2/RR [4] has been used whether it could be able to model the SPERT IV transient experiment. This work has been done under the framework of the International Atomic Energy Agency Coordinated Research Project (CRP) 1496 "Innovative Methods in Research Reactor Analysis: Benchmark Against Experimental Data on Nuetronics [sic] and Thermal Hydraulic Computational Methods and Tools for Operation and Safety Analysis of Research Reactors," the aim of which is to develop the innovative research reactor modeling methods and to assess and qualify the computational codes for application in the safety analysis of various research reactors. Being the member of this CRP project, the authors have been delivered the design specifications with tests results of SPERT IV transient experiment for analysis with the computer code they have.

\section{SPERT IV Transient Tests Description}

The SPERT IV D-12/25 core was a light water-cooled and moderated, pool-type reactor with provisions for both upward forced and natural convection cooling. The core is composed of 25 type-D standard fuel assemblies in a square five by five section of the nine by nine supporting grid. The 


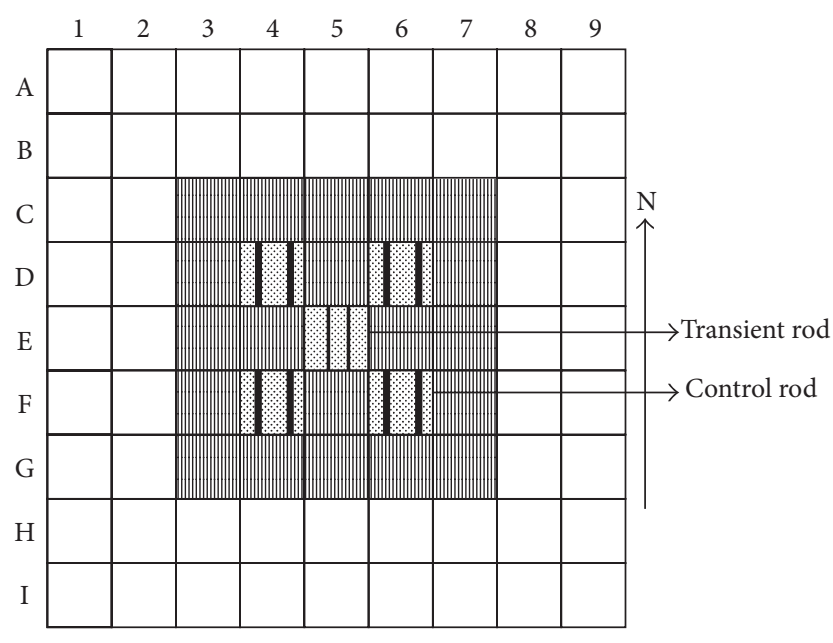

FIGURE 1: SPERT1V D-12/25 core configuration.

core configuration is provided in Figure 1. Each standard fuel assembly contained 12 removable fuel plates. Four gangoperated boron-alloy double-blade control rods and one transient rod of the same style located in the center of the core were accommodated in the standard fuel assembly replacing its six fuel plates. For complete specification of the reactor components, Day [5] can be referred to. The test sequence is illustrated in Figure 2 where five transient phases are noticed. There are 39 transient tests reported for SPERT IV reactor benchmark analysis [5]. The published results for peak power, peak cladding temperature, and energy released are provided in the document [5] with respect to a number of control variables such as initial reactor power, reactivity insertion, bulk moderator-coolant temperature, hydrostatic head, and coolant circulation rate. Table 1 shows these tests are divided into five groups in terms of coolant flow rate. The first group corresponds to flow rate zero with coolant velocity zero, the second group corresponds to $500 \mathrm{gpm}$ with coolant velocity $0.365 \mathrm{~m} / \mathrm{s}$, the third group corresponds to $1000 \mathrm{gpm}$ with coolant velocity $0.731 \mathrm{~m} / \mathrm{s}$, the fourth group corresponds to $2500 \mathrm{gpm}$ with coolant velocity $1.828 \mathrm{~m} / \mathrm{s}$, and the fifth group corresponds to $5000 \mathrm{gpm}$ with coolant velocity $3.657 \mathrm{~m} / \mathrm{s}$. Also, each test of each group is seen to differ with respect to initial ambient reactor temperature, power, reactivity insertion, and corresponding period. It is also apparent that the tests in each group were performed in a progressive manner by increasing the amount of positive insertion of reactivity so the corresponding transient period is found shorter. Most of the tests in the series were initiated with the reactor critical at a power level of approximately $1 \mathrm{~W}$ which is related to the initial transient period $>15 \mathrm{~ms}$. The remaining tests were performed for $<15 \mathrm{~ms}$ for which the reactor was initially subcritical at a power in the milliwatt range that allows the complete reactivity insertion before power rises to a significant level.

It is to mention that the initial power columned in Table 1 is not directly provided in the SPERT IV documentation. This initial power was considered as $1 \mathrm{~W}$ for transient period $>15 \mathrm{~ms}$ and was considered at milliwatt range for transient period $<15 \mathrm{~ms}$. Only tests with forced upward coolant flows
$500 \mathrm{gpm}, 1000 \mathrm{gpm}, 2500 \mathrm{gpm}$, and $5000 \mathrm{gpm}$ were taken into consideration for the present simulation. These ranges of tests are found to consider $18 \mathrm{ft}$ hydrostatic head.

\section{EUREKA-2/RR Code and Modeling the SPERT IV Core}

EUREKA-2/RR is a revised version of EUREKA-2 which was originally developed by JAEA for reactivity accident analysis for nuclear power plants. A heat transfer package is added to EUREKA-2 to modify it to EUREKA-2/RR where the heat transfer correlations considered in the heat transfer package were obtained or estimated from the heat transfer experiments in which the thermal hydraulic features of the upgraded JRR-3 core were properly reflected. This causes the EUREKA-2/RR to be more applicable to research reactors which are operated under low pressure and low temperature conditions using plate-type fuel, just like the JRR-3M. In this special heat transfer package, for heat transfer coefficients of single-phase flow, Dittus-Boelter correlation is used for forced convection mode and Collier correlation for natural convection mode; Chen correlation is used for heat transfer coefficients of two-phase flow and then ONB (onset of nucleate boiling) is determined by comparing the heat flux predictions from Dittus-Boelter correlation and the modified Chen correlation. When the heat flux by the modified Chen correlation is greater than the heat flux by the Dittus-Boelter correlation, it is justified that the nucleate boiling starts under the saturation condition or under the subcooled condition [5]. For DNB heat flux calculation, the code used SudoKaminaga correlation based on JRR-3 thermal hydraulic experiment [6]. One-dimensional time dependent heat conduction equations are used for heart conduction model. The thermal hydraulic solution is assumed to contain one-dimensional homogeneous fluid with the vapor and liquid phases in thermodynamic equilibrium.

EUREKA-2/RR does RIA analysis by coupling neutronics, thermal hydraulics, and point kinetics, as shown in Figure 3. Hence, calculation of neutronics is of first consideration and MVP code [7] has been used for this purpose. Kaminaga developed three supporting codes which are DISSUE, ICETEA, and PREDISCO [8] to produce necessary input for developing model in EUREKA-2/RR. DISSUE calculates power fraction and reactivity weighting factors for each heat slab, ICETEA produces coolant temperature distribution, and PREDISCO calculates coolant pressure distributions for different volumes of corresponding channels.

For modeling SPERT IV core in EUREKA-2/RR code, only fuel region with upper and lower plenum was considered. The whole core was divided into several regions called channels in the code. These channels differ from each other by power generation, coolant mass flow rate, and hydraulic diameters. The core contains 20 standard fuel assemblies and 5 control fuel assemblies. Each standard fuel assembly contains 12 fuel plates and each control fuel assembly contains 6 fuel plates. All these fuel assemblies are distributed into 5 distinct channels. The distribution of these fuel assemblies among the channels is made on the basis of what value 


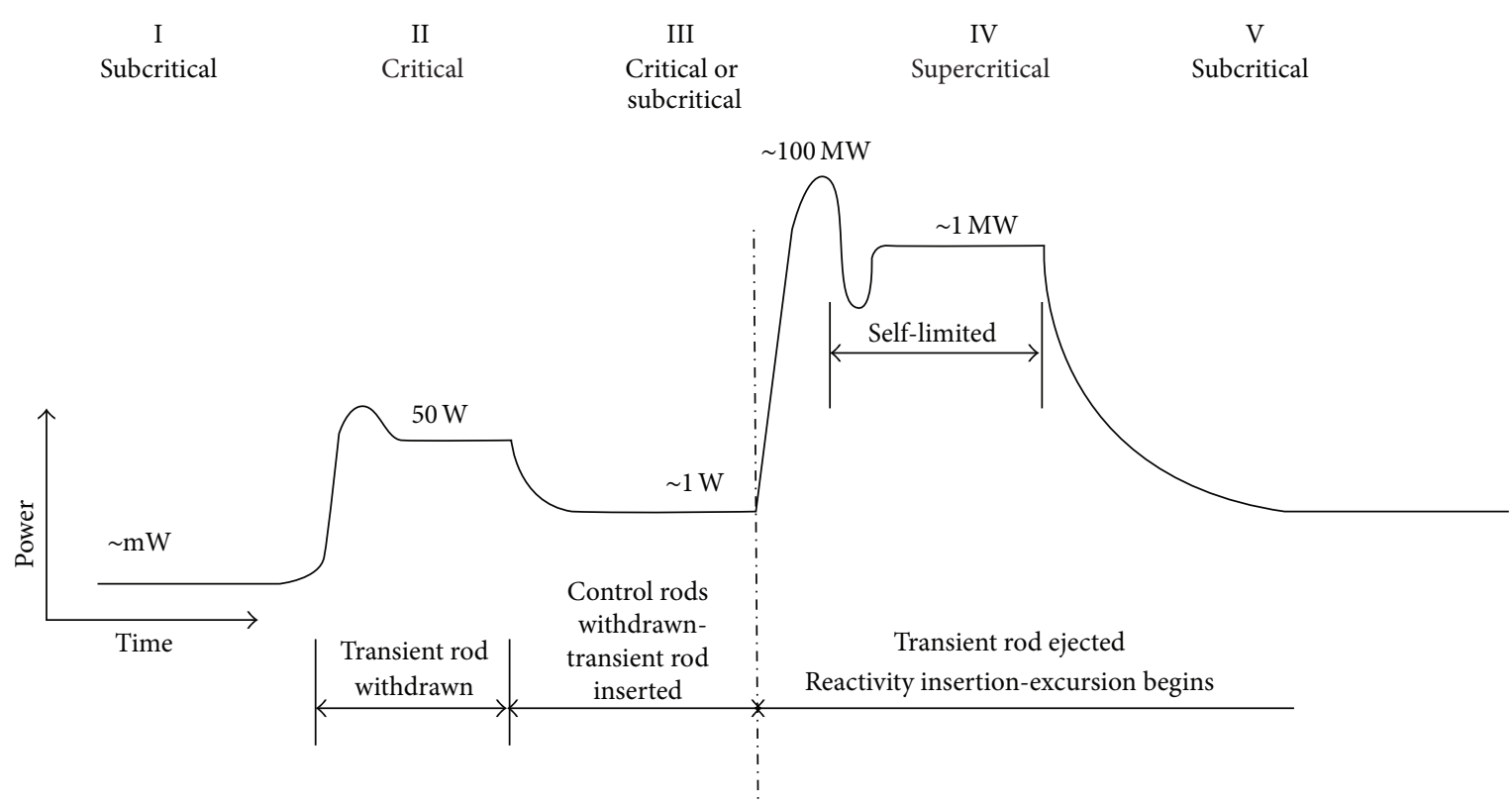

FIGURE 2: Sequences followed in reactivity insertion tests of SPERT IV D-12/25 core.

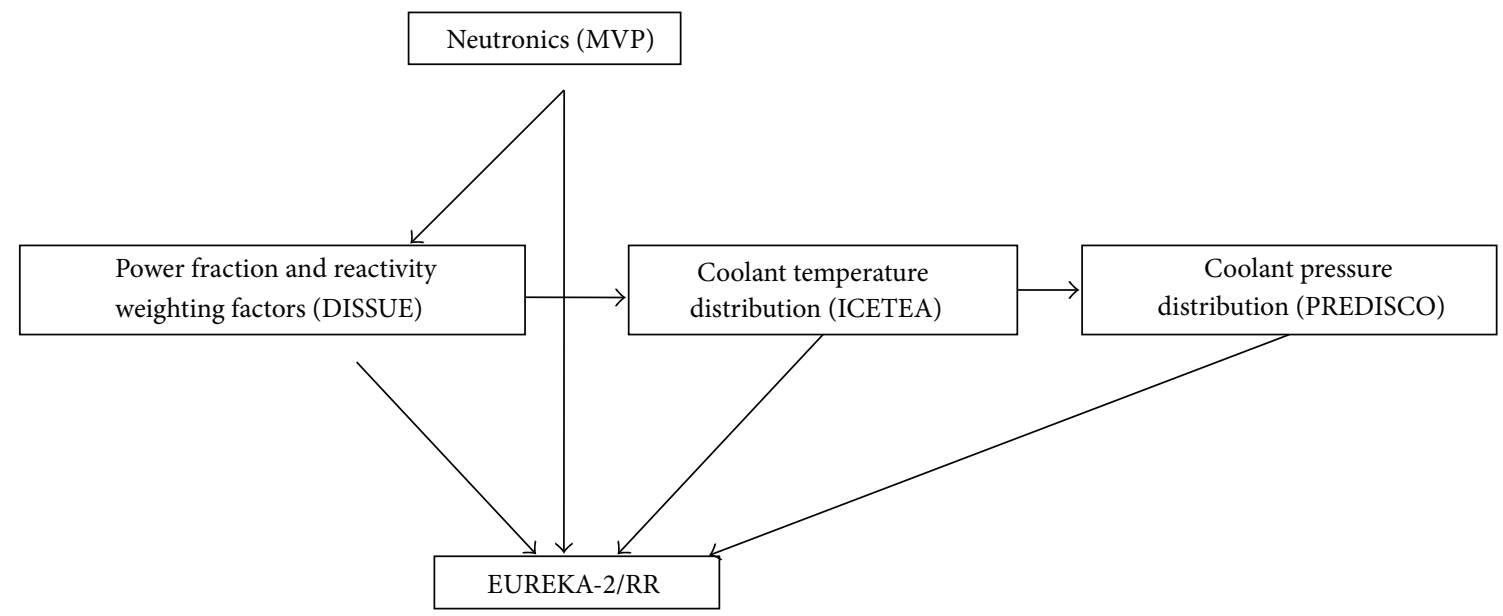

FIGURE 3: An outline of the process followed in preparing input of EUREKA-2/RR.

of radial power peaking factors, $F_{R}$, each fuel assembly contains. Table 2 provides the average radial peaking factors calculated for each fuel assembly. The computer code MVP version 2.0 [5] has been used for neutronics calculation considering cold, clean SPERT IV core using the crosssection library based on JENDL-3.3 [9]. Initially, the fuel assemblies have to be arranged in decreasing order of $F_{R}$ that starts from the maximum value of 1.37322 as seen in Table 2 . Channel-1 is chosen as the hottest channel that contains a single fuel plate of the hottest fuel assembly E6 with the maximum $F_{R}$. Accordingly, channel- 2 contains the remaining fuel plates of E6 along with the other 7 fuel assemblies, channel- 3 contains 10 fuel assemblies, channel- 4 contains 2 fuel assemblies together with 2 control fuel assemblies, and channel-5 contains the last three control fuel assemblies. Also, the axial peaking factor distribution calculated for the hottest fuel plate is given in Figure 4. The fuel assemblies in each channel are defined by heat conductors called heat slabs while the coolant in the channel is represented by several nodes and junctions. In the present model, each channel consists of 10 heat slabs along with 10 nodes (volumes) and 11 junctions as shown in Figure 5. The model in total then consists of $52 \mathrm{vol}-$ umes, 50 heat slabs, and 56 junctions. According to Figure 5, junction number 56 is the fill junction used to simulate the primary coolant flow in the core. Coolant mass flow rates along the channels for different flow rates are provided in Table 3. Table 4 contains the kinetic parameters that were used during simulation [5]. Other necessary input parameters are taken also from the report of Day (2009) [5]. However, some parameters such as friction and resistance coefficients, 
TABLE 1: Transient tests for SPERT IV.

\begin{tabular}{|c|c|c|c|c|c|c|}
\hline Group & Test number & Reactivity (\$) & Period (msec) & $T_{i}\left({ }^{\circ} \mathrm{C}\right)$ & Flow (gpm) & Initial power $(\mathrm{W})$ \\
\hline \multirow{19}{*}{1} & $\mathrm{~B} 1$ & 0.80 & 980 & 19.0 & 0 & 1 \\
\hline & B2 & 0.88 & 598 & 20.0 & 0 & 1 \\
\hline & B3 & 0.92 & 374 & 21.8 & 0 & 1 \\
\hline & B4 & 0.98 & 190 & 20.9 & 0 & 1 \\
\hline & B5 & 1.04 & 107 & 22.2 & 0 & 1 \\
\hline & B6 & 1.11 & 62.4 & 22.4 & 0 & 1 \\
\hline & B7 & 1.15 & 49.8 & 22.2 & 0 & 1 \\
\hline & B8 & 1.26 & 29.6 & 22.4 & 0 & 1 \\
\hline & B9 & 1.40 & 19.6 & 22.4 & 0 & 1 \\
\hline & $\mathrm{B} 10$ & 1.53 & 15.8 & 20.5 & 0 & 1 \\
\hline & B11 & 1.54 & 14.5 & 22.2 & 0 & 0.001 \\
\hline & B12 & 1.68 & 11.7 & 22.3 & 0 & 0.001 \\
\hline & B13 & 1.82 & 10.1 & 22.2 & 0 & 0.001 \\
\hline & B14 & 1.91 & 8.48 & 22.0 & 0 & 0.001 \\
\hline & B15 & 2.00 & 7.83 & 19.9 & 0 & 0.001 \\
\hline & B16 & 2.14 & 7.0 & 19.8 & 0 & 0.001 \\
\hline & B17 & 1.40 & 21.3 & 22 & 0 & 1 \\
\hline & B18 & 1.68 & 12.0 & 21.8 & 0 & 0.001 \\
\hline & B19 & 1.91 & 8.83 & 21.7 & 0 & 0.001 \\
\hline \multirow{4}{*}{2} & B20 & 0.88 & 560 & 21.9 & 500 & 1 \\
\hline & B21 & 1.14 & 54.2 & 22.8 & 500 & 1 \\
\hline & B22 & 1.66 & 11.9 & 23.3 & 500 & 0.001 \\
\hline & B23 & 1.80 & 10.1 & 23.2 & 500 & 0.001 \\
\hline \multirow{6}{*}{3} & B24 & 0.88 & 529 & 22 & 1000 & 1 \\
\hline & B25 & 1.04 & 103 & 22.5 & 1000 & 1 \\
\hline & B26 & 1.14 & 54.5 & 22.8 & 1000 & 1 \\
\hline & B27 & 1.39 & 20.0 & 23 & 1000 & 1 \\
\hline & B28 & 1.66 & 12.3 & 22.9 & 1000 & 0.001 \\
\hline & B29 & 1.80 & 10.4 & 22.9 & 1000 & 0.001 \\
\hline \multirow{4}{*}{4} & B30 & 0.88 & 531 & 22.5 & 2500 & 1 \\
\hline & B31 & 1.14 & 52.1 & 22.7 & 2500 & 1 \\
\hline & B32 & 1.66 & 12.2 & 22.6 & 2500 & 0.001 \\
\hline & B33 & 1.80 & 10.0 & 23.2 & 2500 & 0.001 \\
\hline \multirow{6}{*}{5} & B34 & 0.88 & 516 & 21.9 & 5000 & 1 \\
\hline & B35 & 1.05 & 104 & 22.0 & 5000 & 1 \\
\hline & B36 & 1.14 & 49.3 & 22.4 & 5000 & 1 \\
\hline & B37 & 1.39 & 20.7 & 20.7 & 5000 & 1 \\
\hline & B38 & 1.66 & 12.2 & 23.4 & 5000 & 0.001 \\
\hline & B39 & 1.80 & 10.1 & 23.7 & 5000 & 0.001 \\
\hline
\end{tabular}

fuel and cladding thermal properties, and plenum characteristics have been approximated due to unavailability of the data.

\section{Results and Discussion}

The calculated peak power values together with the experimental values for observed tests under forced convection are summarized in Table 5. It is seen that the calculation has provided peak power values which are too low compared to the experimental values and these underestimating the experimental measure in most cases exceed by an amount from $60 \%$ to $70 \%$. But for peak clad temperature estimation, this difference is found in comparison to be largely reduced. Figures 6 to 9 present comparison between experimental and calculation results of peak clad temperature for all the tests identified as B20 to B39.

Figure 6 is for group 2 with 500 gpm flow rate which consists of four tests identified as B20, B21, B22, and B23. Figure 8 presents group 4 that contains four tests B30, B31, 


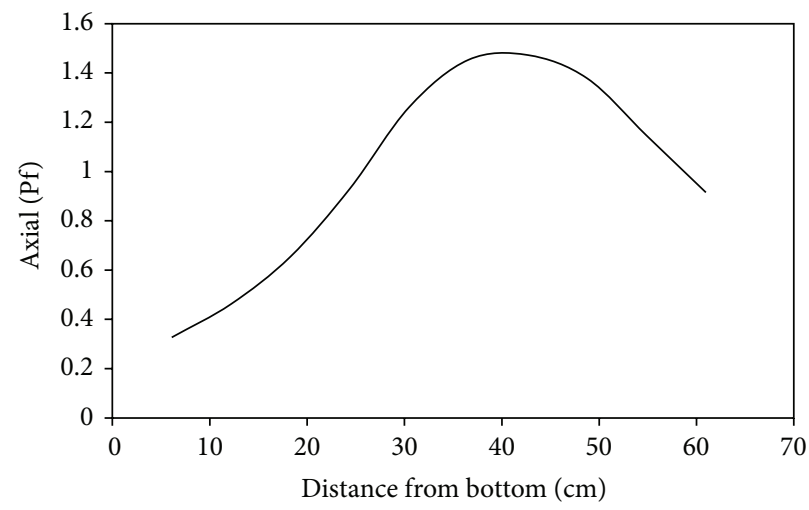

FIgURE 4: Axial peaking factors along the hottest plate.

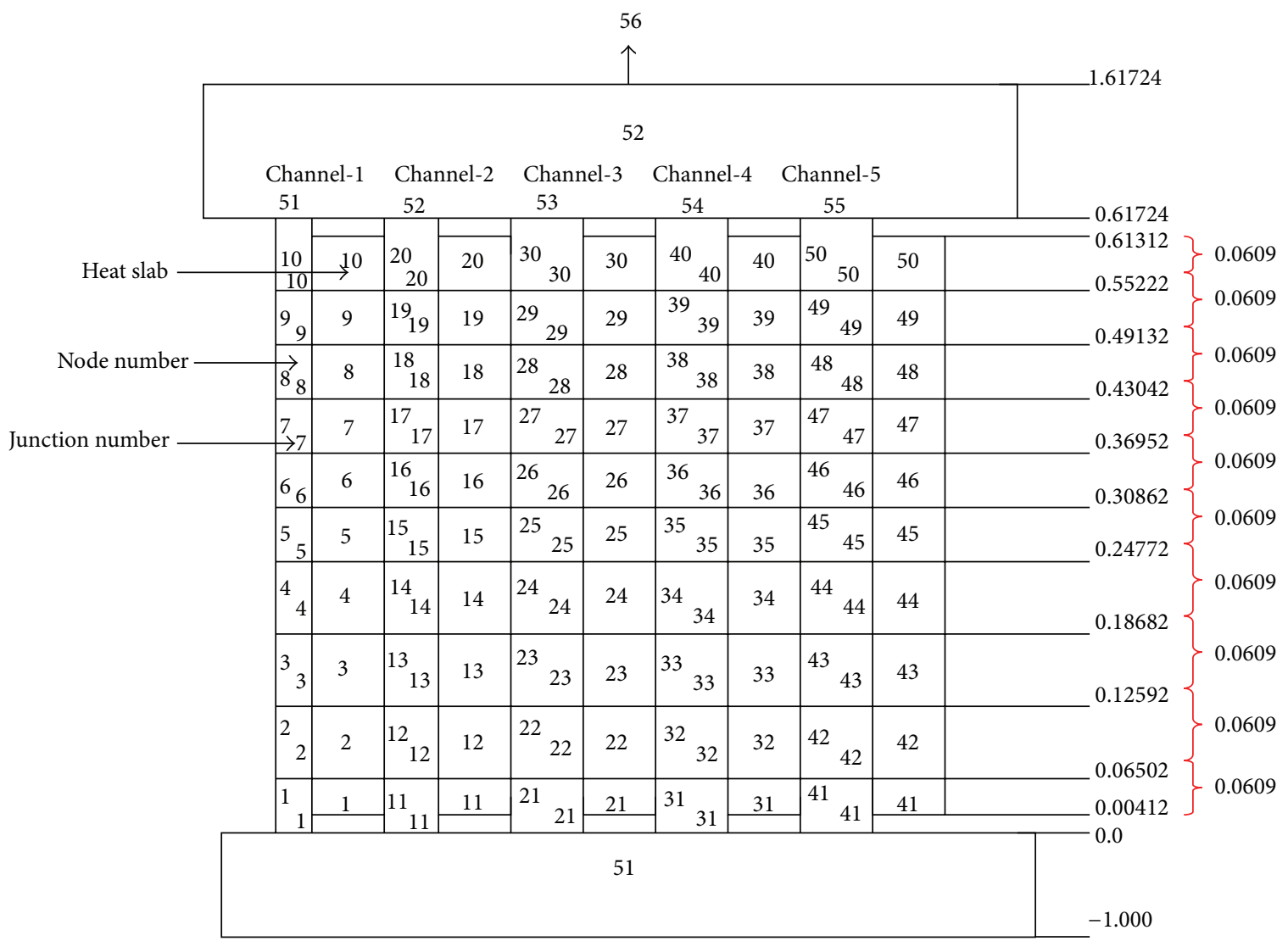

FIGURE 5: Schematic diagram of the model prepared for EUREKA-2/RR analysis.

B32, and B33 but with different flow rate, $2500 \mathrm{gpm}$. Similarly, Figure 7 presents group 3 with 6 tests with the identifications B24, B25, B26, B27, B28, and B29 with coolant flow rate $1000 \mathrm{gpm}$ and Figure 9 reflects group 5 with six tests B34, $\mathrm{B} 35, \mathrm{~B} 36, \mathrm{~B} 37, \mathrm{~B} 38$, and $\mathrm{B} 39$ with flow rate $5000 \mathrm{gpm}$. It is evident from these plots that results of EUREKA-2/RR code and SPERT IV tests vary within $12 \%$ for almost all the tests. However, some inconsistency is noticed for few tests which correspond to a reactivity insertion less than $\$ 1$. If one traces back work of Chatzidakis et al., 2012 [3], it is found that three DNB correlations, namely, Tong, Mirshak, and Bernath, facilitated in the PARET code, have been applied for a range of tests to identify use of which correlation provides peak clad temperature values that agree with the experimental results. Peak power values have not been shown to compare with the experiment in this paper. It is identified in this paper that the peak clad temperature values estimated using the Tong DNB correlations provide results that vary within $50 \%$ with experimental results wherever it seems that Mirshak and Bernath correlation fail to incorrectly predict 


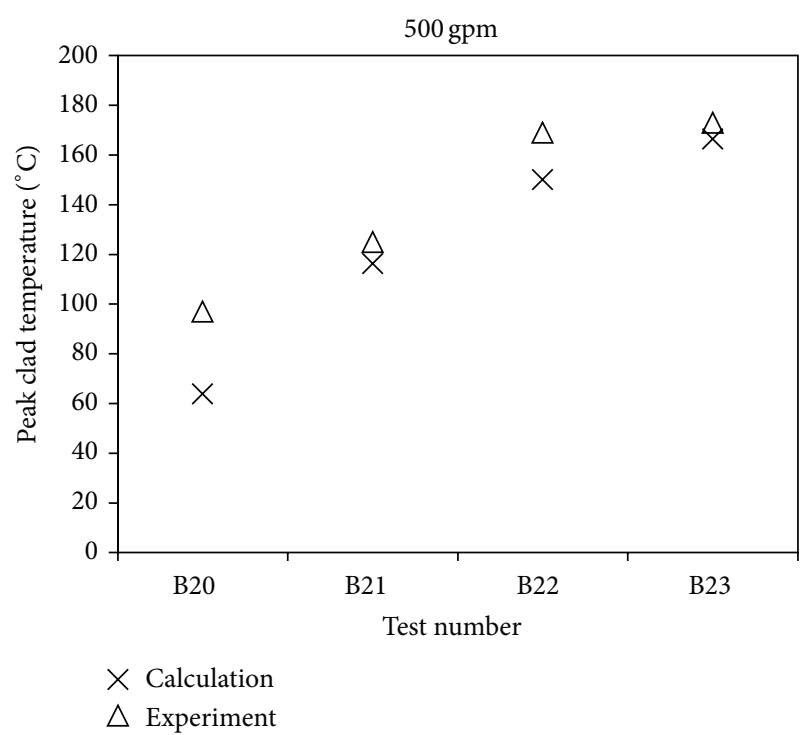

Figure 6: Peak clad temperature values for the tests of group 2.

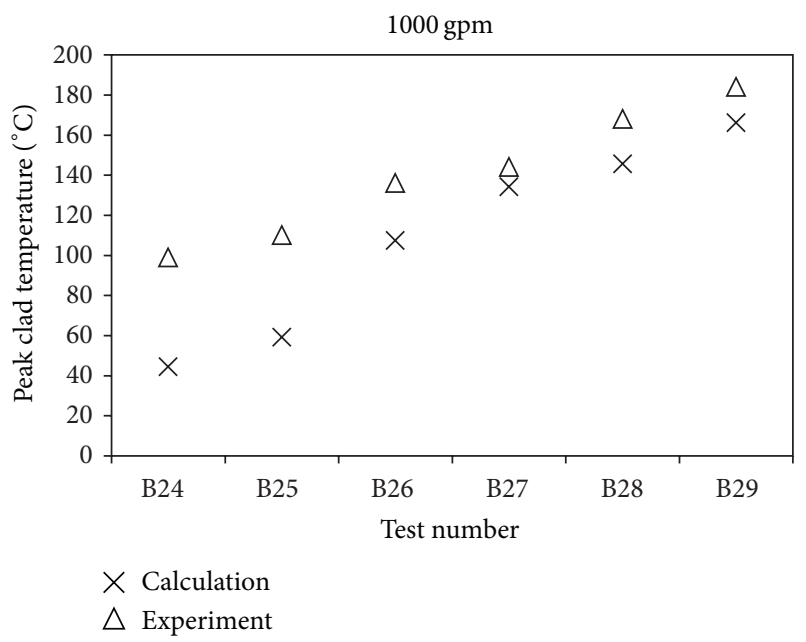

FIgURE 7: Peak clad temperature values for the tests of group 3.

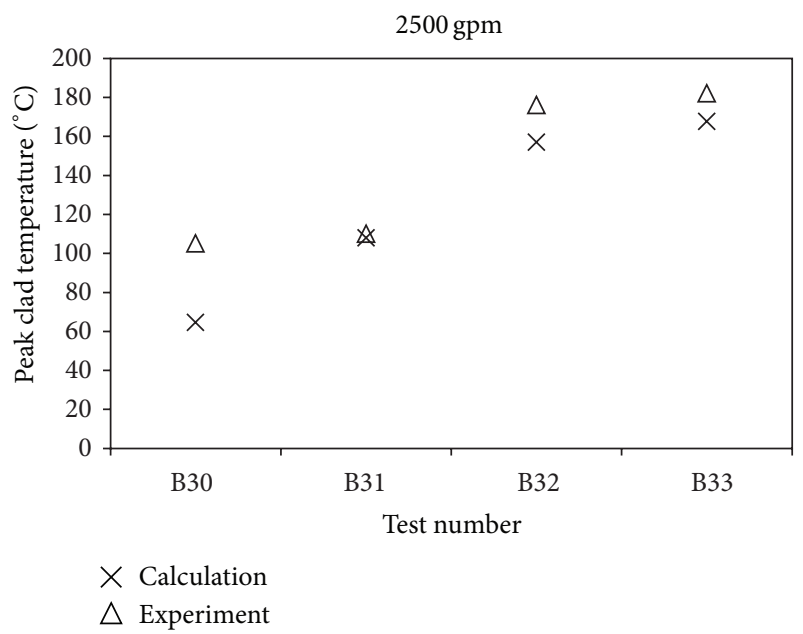

FIGURE 8: Peak clad temperature values for the tests of group 4.
TABLE 2: Channel distributions in EUREKA-2/RR.

\begin{tabular}{|c|c|c|c|c|}
\hline $\begin{array}{l}\text { Fuel cell } \\
\text { number }\end{array}$ & $\begin{array}{l}\text { Radial peaking } \\
\text { factors (MVP) }\end{array}$ & Channels & $\begin{array}{l}\text { Number of } \\
\text { fuel cells }\end{array}$ & $\begin{array}{c}\text { Number of } \\
\text { fuel plates }\end{array}$ \\
\hline E6 & 1.37322 & 1 & $1 / 12$ & 1 \\
\hline E6 & 1.37322 & \multirow{8}{*}{2} & \multirow{8}{*}{$7+11 / 12$} & \multirow{8}{*}{95} \\
\hline F5 & 1.37105 & & & \\
\hline $\mathrm{E} 4$ & 1.36998 & & & \\
\hline D5 & 1.36887 & & & \\
\hline E7 & 1.15432 & & & \\
\hline G5 & 1.14816 & & & \\
\hline E3 & 1.14151 & & & \\
\hline $\mathrm{C} 5$ & 1.13272 & & & \\
\hline D7 & 1.04837 & \multirow{10}{*}{3} & \multirow{10}{*}{10} & \multirow{10}{*}{120} \\
\hline F7 & 1.04519 & & & \\
\hline D3 & 1.04256 & & & \\
\hline G6 & 1.04235 & & & \\
\hline F3 & 1.04180 & & & \\
\hline G4 & 1.04120 & & & \\
\hline C6 & 1.03932 & & & \\
\hline $\mathrm{C} 4$ & 1.03897 & & & \\
\hline $\mathrm{C} 7$ & 0.83797 & & & \\
\hline G3 & 0.83581 & & & \\
\hline $\mathrm{C} 3$ & 0.83525 & \multirow{4}{*}{4} & \multirow{4}{*}{4} & \multirow{4}{*}{36} \\
\hline G7 & 0.83392 & & & \\
\hline E5 & 0.81652 & & & \\
\hline F6 & 0.61168 & & & \\
\hline D6 & 0.61119 & \multirow{3}{*}{5} & \multirow{3}{*}{3} & \multirow{3}{*}{18} \\
\hline $\mathrm{F} 4$ & 0.60960 & & & \\
\hline D4 & 0.60847 & & & \\
\hline
\end{tabular}

the system response. In contrast EUREKA-2/RR code does not contain Tong, Mirshak, and Bernath correlations but it has Sudo-Kaminaga correlation for DNB heat flux calculations. Although peak clad temperature values are found to agree reasonably well with the experiment, the difference between code and experiment in calculation of peak clad temperature with the experiment whether due to the DNB correlation or other parameters needs to be identified.

In general, EUREKA-2/RR code is shown to provide conservative estimates of peak power and also of peak clad temperature values which in turn indicates whether the model developed is able to accurately represent the physical process involved in RIA scenarios of SPERT IV. Various input parameters, say, DNB correlation, kinetic parameters, and feedback coefficients, or the assumptions or misinterpretation of specifications considered during modeling or any limitations of code as well need to be examined seriously whether they cause effects in modeling such RIA tests.

\section{Conclusion}

As a part of validation, SPERT IV reactor model is developed to simulate the RIA (reactivity initiated accident) transients. 
TABLE 3: Coolant mass flow rate distributions along the channel.

\begin{tabular}{|c|c|c|c|c|c|}
\hline $\begin{array}{l}\text { Core flow rate } \\
\text { gpm }\end{array}$ & Channel-1 & Channel-2 & $\begin{array}{c}\text { Channel-3 } \\
\mathrm{Kg} / \mathrm{sec}\end{array}$ & Channel-4 & Channel-5 \\
\hline 500 & 0.1520 & 14.4500 & 18.2535 & 6.0849 & 3.6515 \\
\hline 1000 & 0.3041 & 28.9000 & 36.5093 & 12.1706 & 7.3035 \\
\hline 2500 & 0.7600 & 72.2500 & 91.2675 & 30.4245 & 18.2575 \\
\hline 5000 & 1.5205 & 144.5040 & 182.5465 & 60.853 & 36.5175 \\
\hline
\end{tabular}

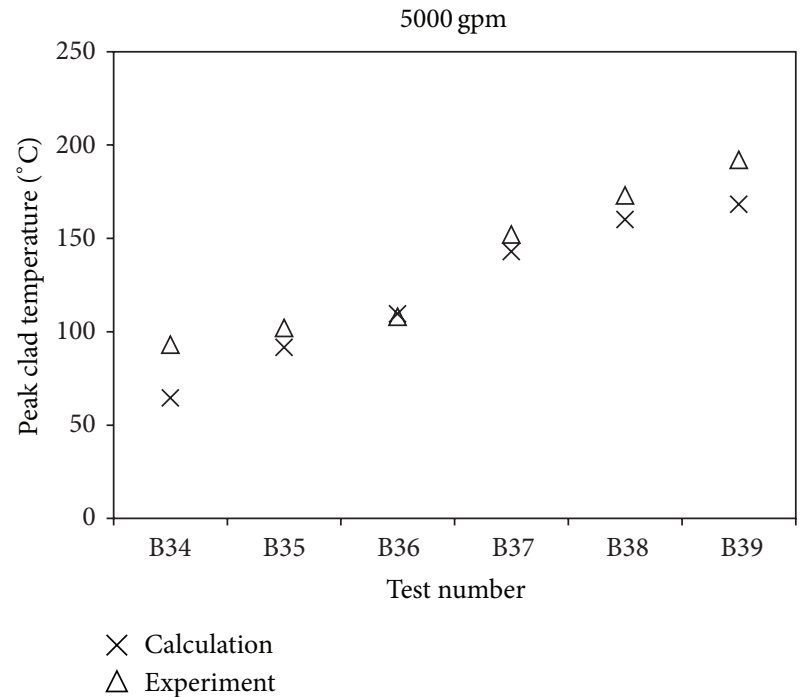

FIGURE 9: Peak clad temperature values for the tests of group 5.

TABLE 4: Kinetic parameters used for SPERT IV transient analysis.

\begin{tabular}{|c|c|}
\hline Parameters & Values \\
\hline $\begin{array}{l}\text { Moderator temperature } \\
\text { feedback coefficient }\left(20-35^{\circ} \mathrm{C}\right)\end{array}$ & $-1.2 థ$ \\
\hline Void feedback coefficient & $\begin{array}{c}-41.5 \$ / \% \text { decrease in moderator } \\
\text { density }\end{array}$ \\
\hline Prompt neutron lifetime & $6.4 \times 10^{-5} \mathrm{sec}$ \\
\hline $\begin{array}{l}\text { Effective delayed neutron } \\
\text { fraction }(-)\end{array}$ & 0.0069 \\
\hline
\end{tabular}

The results that represent the state of modeling do not allow concluding that it is the best model or EUREKA-2/RR is the best code to model such RIA tests of SPERT IV. On the contrary, it is to say that validating the code is a continuous process that is worth pursuing in order to improve the model with an aim of obtaining the best simulation results. To reduce the difference between calculated and experimental values, further efforts then must be paid. More other benchmark cases of SPERT (or others) could be conducted from where suggestions might come to modify the code that could
TABle 5: Peak power (MW) results for tests with forced flow.

\begin{tabular}{lccc}
\hline Test number & Flow rate & Measurement & EUREKA-2/RR \\
\hline B20 & - & 0.9 \\
B21 & 500 gpm & 21.5 & 7.1 \\
B22 & & 422.0 & 77.5 \\
B23 & 435.0 & 150.7 \\
\hline B24 & - & 0.9 \\
B25 & 7.5 & 1.7 \\
B26 & 22.5 & 6.3 \\
B27 & 1000 gpm & 130.0 & 37.2 \\
B28 & & 292.0 & 101.7 \\
B29 & & 425.0 & 150.7 \\
\hline B30 & - & 0.9 \\
B31 & & 22.5 & 6.3 \\
B32 & & 320.0 & 99.4 \\
B33 & & 435.0 & 153.1 \\
\hline B34 & & - & 0.9 \\
B35 & & 9.8 & 2.4 \\
B36 & & 30.2 & 6.4 \\
B37 & & 169.0 & 37.5 \\
B38 & 370.0 & 102.3 \\
B39 & & 505.0 & 148.5 \\
\hline
\end{tabular}

lead the EUREKA-2/RR code to be a more useful tool for research reactor transient analysis.

\section{Conflict of Interests}

The authors declare that there is no conflict of interests regarding the publication of this paper.

\section{Acknowledgments}

The authors are grateful to IAEA for delivering design specification and experimental data of SPERT IV through coordinated research project CRP (1496) "Innovative Methods in Research Reactor Analysis: Benchmark Against Experimental Data on Nuetronics and Thermal Hydraulic Computational Methods and Tools for Operation and Safety Analysis of Research Reactors." 


\section{References}

[1] W. L. Woodruff, "A kinetics and thermal-hydraulics capability for the analysis of research reactors," Nuclear Technology, vol. 64, no. 2, pp. 196-206, 1984.

[2] W. L. Woodruff, N. A. Hanan, and J. E. Matos, "A Comparison of the RELAP5/MOD3 and PARET/ANL codes with the experimental transient data from the SPERT IV D-12/25 series," in Proceedings of the International Meeting on the Reduced Enrichment for Research and Test Reactors, Jackson Hole, Wyo, USA, October 1997.

[3] S. Chatzidakis, A. Ikonomopoulos, and S. E. Day, "PARET-ANL modeling of a SPERT-IV experiment under different departure from nucleate boiling correlations," Nuclear Technology, vol. 177, no. 1, pp. 119-131, 2012.

[4] M. Kaminaga, EUREKA-2/RR: A Computer Code for the Reactivity Accident Analyses in Research Reactors, Japan Atomic Energy Agency, 1996.

[5] S. E. Day, "SPERT-IV reactor specification," IAEA Coordinated Research Project 1496, Innovative Methods in Research Reactor Analysis, 2009.

[6] Y. Sudo, K. Miyata, H. Ikawa, M. Kaminaga, and M. Ohkawara, "Experimental study of differences in dnb heat flux between upflow and downflow in vertical rectangular channel," Journal of Nuclear Science and Technology, vol. 22, no. 8, pp. 604-618, 1985.

[7] T. Mori, M. Nakagawa, and M. Sasaki, "Vectorization of continuous energy Monte Carlo method for neutron transport calculation," Journal of Nuclear Science and Technology, vol. 29, no. 4, pp. 325-336, 1992.

[8] M. Kaminaga, "Preliminary reactivity insertion accidents analysis of the multi-purpose research reactor RSG-GA siwabessy using EUREKA-2 code," JAERI-Memo 03-176, Japan Atomic Energy Research Institute, 1991.

[9] K. Shibata, T. Kawano, T. Nakagawa et al., "Japanese evaluated nuclear data library version 3 revision-3: JENDL-3.3," Journal of Nuclear Science and Technology, vol. 39, no. 11, pp. 1125-1136, 2002. 


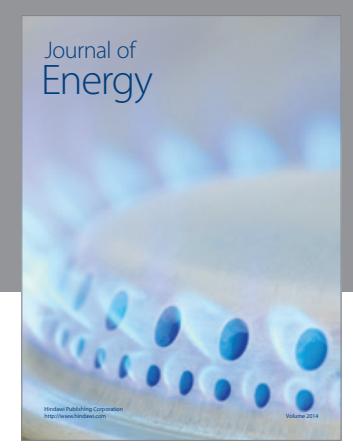

Journal of

Industrial Engineering
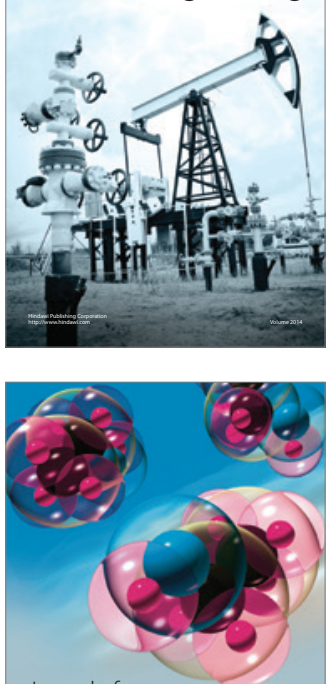

Fuels
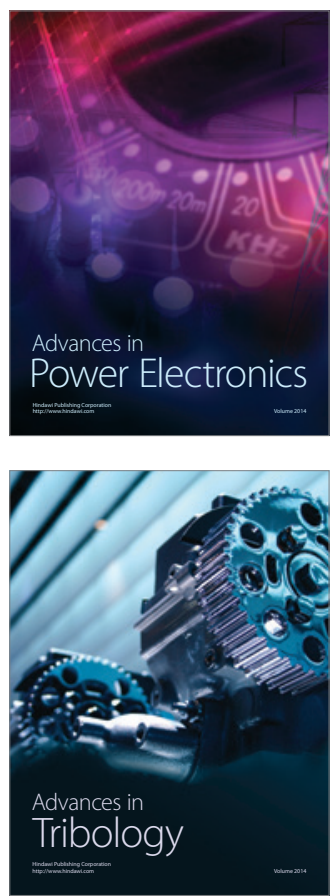

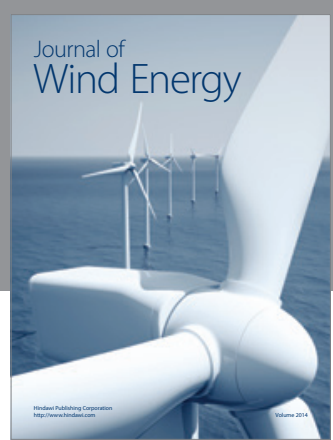

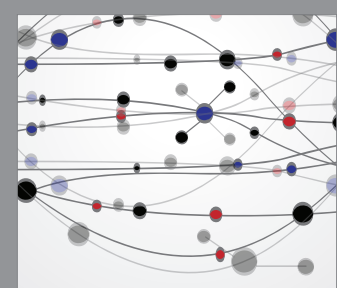

The Scientific World Journal

Submit your manuscripts at http://www.hindawi.com

Journal of

Structures
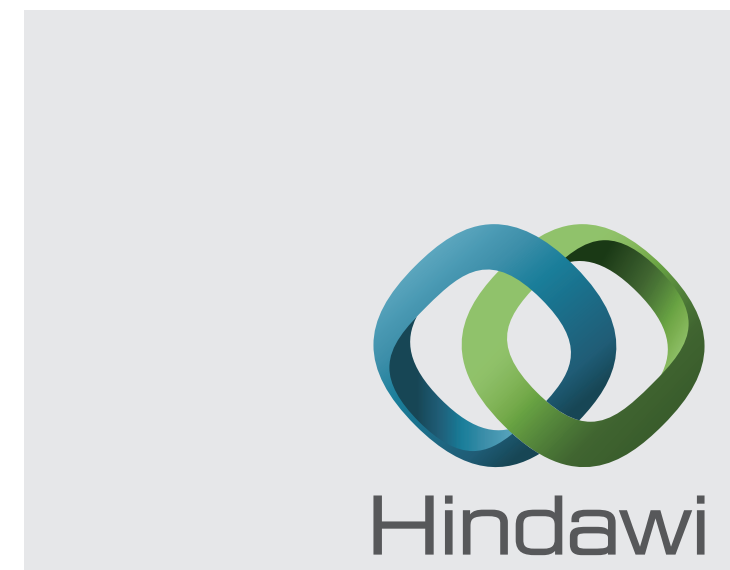

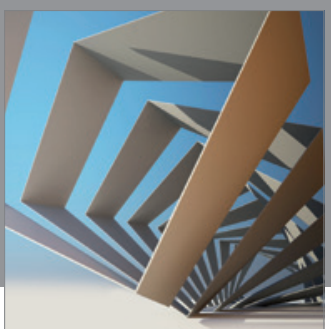

Rotating

Machinery
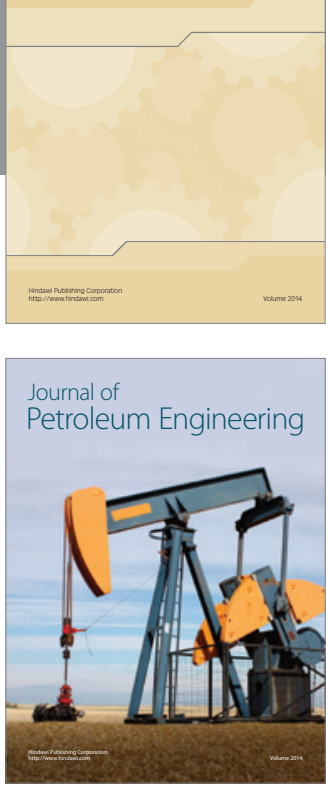

Journal of

Solar Energy
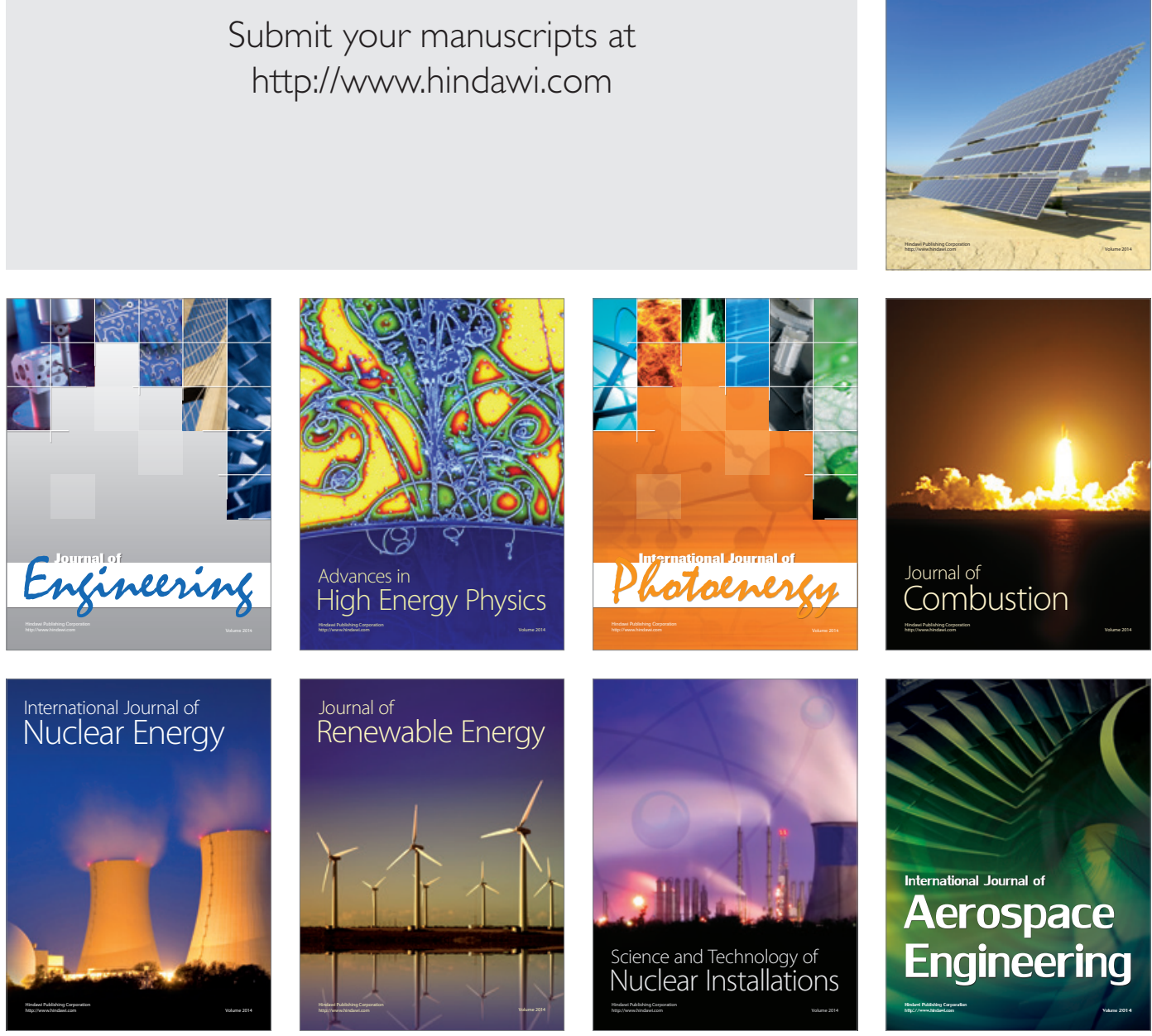